Australian Journal of

Educational Technology

\title{
International collaboration and facilitation of learning environment technology
}

\author{
Colin N Power \\ Assistant-Director General for Education, UNESCO
}

Address to the LETA 94 Conference, Learning Environment Technology Adelaide, South Australia, 25-30 September 1994.

\section{Mr Chairman \\ Distinguished Guests \\ Ladies and Gentlemen}

It is a great pleasure and privilege for me to address LETA 1994 on behalf of UNESCO, and to focus on ways in which countries can work together to share their knowledge and expertise on new technologies in education. It is, of course, a great personal pleasure to be back home again with old friends. It is a privilege in that I have been asked to speak particularly on international cooperation in the creation of new learning environments, on what we in UNESCO are doing to encourage collaboration and how countries like Australia con contribute to the improvement of education in developing countries using the new technologies.

The Conference has as its theme, new information technology and the learning environment. much has already been said about how we will learn in the future and which technologies are likely to shape, if not redefine, learning environments. I will avoid the temptation to gaze into my crystal ball, but I would like to make just four points from an international perspective.

A. First, as has already been said, we are moving towards an information-based society a shrinking world where communication technology is making more and more information available instantaneously to more and more countries and groups. There are now many players and options in the educational- information game, and these cerate new opportunities for, and challenges to, formal education - precipitating changes in its role and function.

B. Second, in the development of educational media and technology, periods of euphoria have alternated with periods of hesitation as innovations have been introduced, but fallen short of expectations. We have learned that technology per se is no panacea to educational 
ills, although it does open up new possibilities for communication and learning. New technologies must be seen to be part of, and extending, existing learning environments. Only those technologies and their associated software which are accessible, accept as relevant and helpful, are of high quality, easy to use and affordable are likely to remain part of the educational landscape.

C. Third, inequalities in access to education, information, the newest technologies and thus to resources and power are increasing within and between countries. There are sharp differences in the learning environment, the potential to utilise technology and the relative priorities of industrialised and developing countries. We must learn which technologies are the most appropriate for which context and find ways of ensuring that the poor and the remote are not further marginalised.

D. Fourth, given the rapidity of developments in the informatics industry and the common challenges facing education worldwide, a new global consensus about the role of technology in education is needed urgently, the objectives of which would include the rapid exchange of knowledge and expertise among countries and between industry and education, education-industry cooperative ventures and the meeting by countries like Australia and by industry of their obligation to assist countries and groups being bypassed by the information highway.

\section{Future Development of Educational Technology}

On the first point, knowledge and options are expanding at an ever increasing rate - scientific knowledge now doubles every two and a half years, and the ways in which this information is being generated, stored, processed and transmitted is being transformed - today $7 \%$ of information is digitised, but, according to the forecasts, by the end of the century $95 \%$ of information will be in a digitised format, with only a third available in text. Computers are becoming twice as fast or half as expensive every two years, more connected smaller and more mobile. CD-ROM technology now means we can store 300,000 pages of text on a single disk. The best interactive multimedia technology incorporate the full range of media, are presented experientially, and encourage self-directed exploration of knowledge. The global market for software is about $\$ 60$ billion, of which about one fifth is educational. Globally we face an ever expanding universe of information and choices, but increasingly we will depend on technology to give us access to this information and to help us find our way.

Formal education systems no longer have a monopoly on knowledge and learning. There are now many players in the information environment of education, industry and culture. For example, by the time young people leave school in the US and Australia, they will have spent an average of 20,000 hours watching television, more than twice the time spent in class, and more and more they will be able to gain access to the new information 
highways through a PC at home. It is clear that our schools and universities cannot continue to cram more and more information into already over loaded curricula and textbooks, or lock young people in boxes and force them to sit listening to teachers or filling out worksheets. Too many education systems, schools and universities around the world are still imprisoned in 19th century educational thinking, seeing the technologies as non- problematic agents for delivery of information, rather than as active agents within a complex educational environment. It is a bit like the cartoon strip Crock in which when a member of the hapless lost patrol suggests using a mirror to signal the fort, the inept patrol leader responds with "That's a great idea... but how do you write a message on a mirror?"

The challenge that organisations like UNESCO, the industries, institutions and governments represented here face is that of helping education systems to move conceptually and practically from the 19th to the 21st century. How can we use the new technologies to give to all - including the poor and the disabled - access to the knowledge and skills they need to be part of our world? Can we make learning a lifetime adventure, a voyage of exploration for those who reject or who are rejected by our existing educational institutions? How can we help teachers to actualise the promise of interactive multi-media systems?

Administrators, planners, curriculum developers and assessment specialists from all parts of the globe need to see and learn at first hand how the new technologies and software can enhance their decision making, programs and networks. We need more lighthouse schools like Berkshire and Blackstock in the US and Burnaby South in Canada to help us to understand how to use the latest interactive multi-media technology. We need hard-headed evaluations of software, and to invest in quality educational packages. We need to share our experiences globally, to tell of breakthroughs and tribulations, to explore the global situation and trends technical trends such as the emergence of third generation systems, financial changes including the push towards private funding, pedagogic changes such as the emphasis on dialogue and exploration of knowledge, and the internationalisation of education and communication.

This is the promise of the new technologies. As an agency concerned about the improvement of education, UNESCO has launched several activities aimed at helping Member States to understand that new technologies are not mere tools but are powerful forces helping to reshape education and its meaning. These activities include

- the International Commission on Education for the 21st Century chaired by Jacques Delors. The Commission's report due next year will advise on what kind of education is needed for what kind of society in the future, and the role of the new information technologies in education will be one of its major themes. UNESCO plans to use the report to provoke reflection, debate and reform in its Member States, individually and collectively. 
- a Forum of Reflection and a new UNESCO program on "Learning without Frontiers" which seeks to ensure that the potential of the new technologies to facilitate access to education and information extends to poor countries and marginalised groups. We have started a project in Central America to develop programs which are sensitive to, and respect, most languages and cultures so that the information highway is not a one way street dominated by one culture and one worldview.

- the second International Congress on Education and Informatics to be held in Moscow in 1996. The first congress held in UNESCO in 1989 brought together for the first time experts, industries and governments (North and South, East and West) to recommend how the new technologies could be used to the benefit of all. UNESCO and the major hardware and software corporations are working closely with Russia to ensure that the second Congress helps us to actualise the global cooperation promised in 1989.

\section{From Theory to Practice}

Of course, UNESCO is not just a global think-tank dreaming and talking about what the world might or ought to be like. We are also a technical agency very much involved in the day-to-day problems of moving from theory to practice. In 1967, UNESCO published Wilbur Schramm's seminal work The new media: Memo to educational planners. Since then, this tradition of moving from theory to practice has remained unbroken. So over the years, we have been involved in many technology-based innovations ranging from a large ETV project in the Ivory Coast, the experimental SITE satellite project in India, educational media projects in El Salvador, interactive radio in Nicaragua, to a research project involving 25 countries on the impact of computer use in school on children's meta-cognitive development.

More recently, we have been putting into various languages vast amounts of information about education systems, institutions and programs on CD$\mathrm{ROM}$; building new educational networks to promote the rapid transfer of scientific information from the universities in the north to universities in the south and the east; linking UNESCO's associated schools in various regions. We are developing affordable and user-friendly packages for educational planners and decision makers in developing countries; producing basic literacy and primary education materials in mother tongue languages and basic teaching materials for thousands of refugee children, street children and cultural minority groups; training teachers and planners in developing countries through the distance mode; and equipping places like Palestine and Eritrea with the technology needed to set up, plan and manage their new Ministries of Education.

All of this work leads me back to my second point, and to remind countries and institutions that the effectiveness of any technology or system depends very much on how it is used and how appropriate it is in the context in which it is being used and for those using it. In the end, it is design, quality control and people that count. 
Countries and institutions often get anxious about the risk of missing the train to the 21st century. In a competitive global economy, governments in the west look nervously at their trading partners, and institutions, aid at ways to convince others that they are at the competitive edge. Meanwhile, developing countries everywhere are struggling to meet their vast and urgent educational demands in the face of crippling shortages of money, qualified teachers and appropriate textbooks. Many Ministers of Education are looking to distance education and new technologies to prop tip their ailing education system.

This pressure and these unrealistic expectations have in the past led to expensive mistakes. There has been much investing in hardware such as buying computers for schools or installing satellite systems, without attending to questions of use. We must pay attention to the real costs and to the technological and human challenges involved in using new technologies in each context, in each new application. In their rush to push all onto the technology bandwagon, advocates tend to overlook the following issues:

- the cost of buying the new equipment is only a small fraction of the real costs involved: schools and universities were built long before, and were not designed to accommodate the new technologies and costly modifications may be needed; initial costs do not include the costs of maintaining the equipment or paying for on-line services

- the technology is only as good as its software, and given that to date the investment by industry in educational software has been limited, there are not many low cost, high quality educational packages available to beam around the world via satellite or stored on disk which can easily be adapted to fit existing curricula or higher education programs

- someone will have to train the teachers to use the new services and provide them with incentives to do so, and few technology-shy teachers who have difficulty finding time to cope with the multitude of demands placed on them can be expected to quickly learn how to take advantage of new technologies.

- spanning the globe with networks of communication does not necessarily lead to learning or to improved performance in examinations or on the job. Learning is an active process of constructing meaningful structures of knowledge, learners need to be actively intellectually engaged and to convince others including those who will assess them of their competence.

I do not wish to be a bearer of bad tidings. But experience indicates that we should be more modest in our expectations and be prepared to meet the challenges and obstacles inherent in introducing new technologies into established educational institutions and systems. Their effectiveness rests on how well they are designed, deployed and ultimately used within specific contexts. 


\section{Equity and Gaps in Utilisation of New Technologies}

As most of my professional life is devoted to helping developing countries and countries undergoing massive restructuring of their societies to cope with their educational problems, I should now like to turn to the third issue I raised in my introduction - equity, and to re- stress that UNESCO's prime concern is education for all, as this is the foundation for a culture of peace and equitable development.

While computers move more than a trillion dollars around the world's financial markets every 24 hours and military spending equals the combined income of half of the world's people, most of the villages and towns in which the world's poor live have no electricity, no phones, no television, few books and, I am sorry, no CD-ROMs.

UNESCO estimates put the number of illiterates today at about 900 million. About one third of the world's population cannot read or write, and have no access whatsoever to even the most rudimentary of information technologies, the printed text. Moreover, there are about 130 million children who have no access to even a limited primary education, and millions more who drop out after only one or two years of schooling. UNESCO's World Education Report estimates the educational life expectancy of a girl in Niger at 1.4 years, compared with 16.5 years in Canada. And sadly, UNESCO education and science reports show that the gaps and inequalities in education and access to information between the rich and poor have widened alarmingly in the past decade.

At the World Conference on Education for All held in 1990 in Thailand, educational and political leaders from almost all countries throughout the world recognised that conventional means of educational delivery were inadequate to solve the problems of illiteracy or to reach the targets of universal primary education by the year 2000. Education for all implies education by all, and by all possible means. Thus, the World Conference recognised the importance of modern communication media in this context calling for "an expanded vision that surpasses ... conventional delivery systems" and which "utilises all available instruments, many channels of information ... to convey essential knowledge and inform and educate people on social issues."

The World Conference focussed on the basic learning needs of all, with girls and women, those living in isolated areas, the disabled, refugees and ethnic minorities as targets. Thus the prime focus is on promoting for all the learning of essential knowledge and skills, not just attendance at school. How then do we harness the potential of the new technologies to facilitate learning for all including those with limited access to formal education, and those who do not easily fit the Procrustean beds which our schools and universities normally provide?

With the increase in the chances of survival but increases in armed conflict and poverty, the number of refugees, displaced persons and disabled is 
growing dramatically. There are now over 43 million refugees and displaced persons, and over 290 million people with moderate to severe mental or physical disabilities. Most refugees and handicapped live in great poverty. For them, the right to basic education is frequently denied. In developing countries, host governments usually cannot or do not make provision for the education of refugees. It is generally believed that in poor countries that disability is punishment from God, evil spirits or magic. Generally less than $2 \%$ of even mildly disabled children in these countries are in school. UNESCO has been actively promoting the integration of the handicapped in regular schools, and has been providing training with the help of multi-media packages for educators. In most cases, very simple measures using simple technology can make it possible for millions of excluded children to gain access to basic education. At the same time, we must also pursue the potential of new technologies, such as IBM's deaf literacy program Hands-On, Voice Type and Phone Communicator.

Expanding access to information and education necessitates a blurring of the frontiers between educators and communicators. Formal education systems have much to learn from, and must work closely with, non-formal systems and communication specialists who have concentrated on community building and development. Many professional communicators are using mass media and the techniques of advertising for developmental and instructional purposes - public information campaigns using all media and the techniques of advertising have been used successfully to promote mass literacy, to sensitise and inform the public on environmental, population, health, agriculture and other issues. A well-known example is Sesame Street, but there are many others.

Many of the experimental approaches used in applying the media to the development process have been outside the formal educational environment, aid as a result are not widely known by educators. We do need to break down the bureaucratic separations between Ministries within government and between formal education and the society it is supposed to serve, for too often the system creates barriers to learning rather than promoting learning without frontiers. It has only been through such deliberate experiments and imaginative interventions as the Open University and the Children's Television Workshop that the doors of learning have been opened for those for whom it load closed in the past.

One other issue of considerable concern to UNESCO is that of language and culture. It is very clear that small cultures and even some large ones like French are concerned about the technology-led cultural invasion which is dominated not only by the English language, but more significantly, convey what is predominantly a US world view, a culture which others see as dominated by individualism, consumerism, materialism, entertainment and violence, and which threatens with extinction smaller and weaker cultures.

The advent of satellite communication and cassettes now makes it possible to share information and programs both on real time and on a delayed 
basis. The question is who will control the technology, and will industry work with us to use the technology to preserve cultures and languages which are in danger, and to enable educators from various cultures to share and exchange their views about the kind of education which is appropriate for their children. But will we, from the dominant cultures of the west, listen and learn from them? Or will the new technologies be the vehicles for a new type of cultural colonialism?

If used wisely, the new technology makes it possible for educators from all parts of the world to share the best of their experience and instructional programs, for teachers and children from one country to be in direct contact with teachers and children in another, even though at the moment, cultural and linguistic differences will continue to limit the scale and utility of such exchanges, particularly at the primary and secondary levels. Cross-cultural adaptation and use of successful program concepts and formats make much more sense, especially given the development costs of quality educational programs. Ideally, we should also use the technologies to facilitate collaborative development of programs as well as communication.

Earlier, I mentioned that there are fundamental differences between rich and poor countries in the functions expected of communication technology. At this point, I would particularly like to put the focus on open learning systems and distance education. In developing countries, it is the possibility of addressing massive audiences and of reducing dramatically the cost of delivering educational services to the masses which is most attractive to governments, and industry is interested when there is a large market.

One should add that in the poorer countries, communication systems as well as education systems are weak. They are struggling to meet vast tin met needs and are confronted by formidable obstacles in both education and communication. The hope is that somehow, new technologies can deliver education to the masses through distance education, with achieving economies of scale using simple and available means like radio and rural press. Thus, the villages accessed by the Indian SITE project, the USAID Rural satellite programs, the establishment of a dedicated radio network in Thailand, the national distance education programs in China and India, the proposed low- orbit satellite system for information distribution in Africa, dedicating part of the HISAPAT provision for Spanish domestic communication to Latin American television networking, developing interactive radio across Portuguese speaking countries are all examples of the efforts being made by developing countries to use technology to expand basic education services.

In developing countries, the most likely future audiences for open learning and distance education include adults seeking accreditation and training (eg. untrained teachers) with career improvement as their primary goal; adults with little or no previous formal education seeking basic education and literacy; and young adults who have left school and are seeking a 
substitute form of, or re-entry to, secondary, technical or higher education. In each case, distance education is seen as a potential for overcoming failure in the existing education system, whether formal or as part of employment.

It has been this pressure for access to education, which led African nations at the UNESCO Regional Seminar of Distance Education in Arusha, Tanzania in 1990 to explore ways of promoting distance education in Africa. Similarly, the heads of state of the nine most populous developing countries meeting at the New Delhi Summit in December 1993 launched an unprecedented Joint Initiative on Distance Education linking these countries. The Arab Ministers of Education at their regional ministerial meeting in June this year suggested the establishment of a regional centre for distance education. Heads of States, Ministers of Education and Vice Chancellors of Universities from many countries are seeking the help of UNESCO and others active in the field like the Commonwealth of Learning, ICDE (International Council of Distance Education), the ICDL (International Centre for Distance Learning) and others to help them to develop open learning programs and institutions.

\section{Cooperation in technology education}

This brings me to my fourth area of concern, cooperation in the development of educational technology, the role which countries like Australia can play in helping developing countries and the importance of international solidarity. Educational technology itself is developing in an environment in which education as well as economic and communication systems are being internationalised. We have seen this push most pointedly in the internationalisation of higher education, but there are pressures at all levels for credit transfer, global networks, internationalisation of parts of the curriculum and assessment. Educators have a great deal to gain by working together to share knowledge and expertise in incorporating the use of new technology in education, and must learn to work cooperatively with industry and with other countries to improve the quality and relevance of education in an information age.

Cooperative action is needed in at least seven areas:

1. Awareness, confidence and capacity building

2. Networking between key players in distance education, educational technology

3. Mapping of relevant experience, success and failures

4. Piloting and adapting educational technologies in different settings

5. Shared development of learning systems, programs, learning materials involving inter-country and industry-country exchanges and joint ventures

6. Technology assessment examining the actual, costs and impact of alternative delivery systems.

7. Support for the development of system-wide policy and planning on new technology in education. 
The diffusion of innovation depends on awareness of the technology, confidence that one will benefit from its use, and confidence that one can handle it. Educators from all countries and at all stages in technology use need help in these three areas.

I shall give five recent examples of collaboration in which UNESCO is centrally involved.

First, given the need to inform policy makers of the possibilities and pitfalls involved in the use of new technologies, UNESCO is developing a general policy paper on distance education, open learning systems and the idea of "Learning without Frontiers." In this, we are building on the experience of many countries as well as our own and that of other organisations and professional groups. Later this year we would like to send copies to some of the groups represented here and receive your suggestions.

Second, we are working directly with the COL, ICDE and others to convert UNESCO teacher education packages on Education for All, Special Education, Educational Planning, Environmental Education and others into the distance mode. We would be pleased to work with Australian institutions to that end.

Third, with the help of Norway, a Multi-Channel Learning Base for Eastern and Southern Africa is being set up to develop distance education and open learning systems for this part of Africa.

UNESCO is also working with universities to establish UNESCO Chairs in Distance Education to provide the focus for within country capacity and program development and to create regional networks and support systems.

Fourth, we are encouraging collaboration among educational architects and education technologists in the north-south transfer of technology in the design of schools, colleges and universities. For example, the issue of creating flexible educational buildings was debated in a UNESCO seminar in Berlin as far back as 1974, and the principles developed applied in the design of schools and colleges in Algeria, Libya and Venezuela. Our experience in developing countries is that the problems are not all high tech, the most difficult technology to master may be that which uses the most available, primitive materials: mud and stabilised earth in Yemen, Sudan, Somalia and Mauritania. There is also in the third world the problem of creating a culture of maintenance and not only a technology. Our work in Venezuela, Nicaragua, Philippines, Nepal and Bhutan has contributed to this. Much of our design work in UNESCO is directed at those suffering from natural or man-made disasters. Thus, we are working mainly to advise on design of schools in the tropics and arid regions, earthquake, flood and cyclone-proof schools; to prefabricate and transport schools for Bosnia, build them in refugee camps, and on the rehabilitation of schools, libraries and universities damaged during conflicts. In this 
region, Australia is very much involved in helping design schools able to withstand natural disasters. We have just established a UNESCO Chair in Tropical Architecture at James Cook University to promote the transfer of expertise on the design of schools that are secure against natural disasters, environmentally sensitive and respect or utilise traditional designs.

My final example is another in which Australia is intimately involved. I have mentioned already, the heads of state of the nine most populous countries in which about $70 \%$ of the world's illiterates live, have asked UNESCO to help them reach out to the unreachable, especially girls and women in poor rural areas who for various cultural and financial reasons are, or have been, excluded from basic education. Thus the Joint Distance Education initiative. UNESCO has met several times with the Ministers of Education of these countries to map their needs and potential to develop open learning systems for basic education, and to define an agenda for cooperative action to accelerate the introduction of distance education programs and open learning systems.

Heads of States and Ministers asked me if Australia could help, given that of all countries in the world, it has the oldest and most highly developed system for distance education at the basic education level.

DEET and the Australian National Commission for UNESCO responded very quickly and positively, and so we have now begun with the first step of an ambitious program aimed at building confidence and expertise in not only the nine most populous countries but many other Asian-Pacific countries, and countries in transition like Palestine, Russia and South Africa as well. Thus today 23 key countries around the world cooperating with Australia and UNESCO in this new effort to develop open learning systems.

Key educators from these countries began a three week program of study visits and seminars this month with institutions and experience from all states covered. Participants will learn about the importance of quality, design, planning and support systems in open education. They will see open leaning systems for early childhood and primary school children in action; learn how primary school and literacy materials and programs are designed, developed and delivered, and learn too of the power of the rural lobby; about distance teacher education programs in universities; about the ways in which new technologies are being used to facilitate communication and rapid feedback; how the technology is supporting vocational literacy training and skill development; and facilitating learning about the environment. I have just come from the International Seminar held in Melbourne this week, and can assure you that the countries represented are very keen indeed to work with Australian institutions to develop their open learning systems and programs, and that there is a good chance that many of these cooperative programs will attract the funding they need to make them viable. 


\section{Conclusion}

UNESCO's role is that of promoting cooperation in education among its 182 Member States. Yet, despite the budget constraints, we have done a great deal to pursuade governments and banks to increase their investment in education and thus we are seeing an increase in the number of projects aimed at using new technology to expand access to basic education. We must rely on educators, institutions, forward looking corporations and countries like Australia to support UNESCO initiatives that are currently underway in distance education.

In the development of a the learning environment of the 21st century, new partnerships need to be forged among countries and between industry and educators. To quote, Loll Gerstner, President of IBM:

"I know of no successful company in the world in an unsuccessful society. Good citizenship where we work throughout the world is in the interests of IBM's people, our shareholders and our customers ... IBM combines its technology and its people, in effective partnerships, to bring solutions to the systemic problems that impact society, business and our quality of life."

I know of no successful society which has an unsuccessful education system, and I doubt if any country, no matter how rich or how powerful, can remain successful in an unsuccessful world. The new technologies have created a global village in which the injustice and inequity which exists between and within countries are ever more transparent, and the problems of the third world will more and more impact of the quality of life of the affluent. We must learn to share the benefits of new technology with all and for the benefit of all, or face an increasingly polarised and conflicted world.

Created 20 Nov 94 as

ftp: / / cleo.murdoch.edu.au/ / public/ AustSocEdTechWA/ power-LETA94.txt Revised 25 Aug 96 to http:/ / cleo.murdoch.edu.au/aset/ confs/leta94/powerLETA94.html

Revised 1 Feb 97 to

http: / / cleo.murdoch.edu.au/gen/ aset/ajet/ajet11/ wi95p1.html

Also available as: Power, C. (1994). International collaboration and facilitation of learning environment technology. In J. Steele and J. G. Hedberg (eds), Learning Environment Technology: Selected papers from LETA 94. Canberra: AJET Publications. http: / / www.ascilite.org.au/asetarchives/confs/edtech $94 / \mathrm{mp} /$ power.html

Please cite as: Power, C. N. (1994). International collaboration and facilitation of learning environment technology. Australian Journal of Educational Technology, 10(2), 69-80. http:/ / www.ascilite.org.au/ajet/ ajet10/power.html 